\title{
Kajian Kodikologis atas Surat Sultan Kanoman, Cirebon (COD. OR. 2241 ILLB 17 (No. 80))
}

\author{
Titik Pudjiastuti
}

\begin{abstract}
In the Universitets-Bibliotheek (UB) Leiden there is a pile of Banten letters that are bundled in Cod.Or. 2241 Illb. The 17th (No. 80) letter is a letter from Sultan Anom to the Governour General Willem Arnold Alting and Raad van Indie in Batavia. The content of the letter, which is undated and written in Javanese hanacaraka, is an approval of Sultan given to Raad van Indie for the building of a new house in Indramayu. Based on the codicological analysis of the shape, kind of paper, seal, scripts, and the language, it can be concluded that those letters in the budle were in fact not sent form Sultan Anom of Banten but form Sultan Kanoman of Cirebon.
\end{abstract}

KEYWORDS letters, hanacaraka, codicology

Ketika sedang meneliti surat-surat Banten di Universiteits-Bibliotheek Leiden, saya tertarik pada salah satu surat yang tergabung dalam Cod.Or.2241 Illb. Surat itu ditulis dengan aksara Jawa, bahasa Jawa, tanpa tanggal. Dari isi teksnya dapat diketahui bahwa surat itu adalah surat Sultan Anom, Garage ${ }^{1}$ yang ditujukan kepada Willem Arnold Alting, Gubernur Jenderal dan Raad van Indie di Batavia. Isinya, Sultan Anom menyetujui keinginan Raad van Indie untuk membangun rumah baru di Indramayu yang pembangunannya dikuasakan pada petor Cirebon. Untuk keperluan itu, Sultan juga akan membantu menyediakan bahan-bahan dan peralatan yang berkenaan dengan pembuatan rumah tersebut.

Setelah membaca surat tersebut, timbul beberapa pertanyaan. Pertama, mengapa surat Sultan Anom Cirebon dimasukkan dalam kelompok suratsurat Banten, padahal jelas-jelas teksnya menyebutkan bahwa pengirimnya

\footnotetext{
Dalam teks disebut Garage bukan Cirebon, tetapi Garage telah lama dikenal sebagai nama Sunda dari Cirebon (lihat AB Lapian dan Edi Sedyawati 1996: 5). Sebutan Garage untuk Cirebon juga terdapat dalam Sajarah Banten (SB) pupuh LI - LIII, dalam peristiwa penyerangan Cirebon-Mataram ke Banten yang berlangsung pada pertengahan abad ke-17, disebut Pagarage atau Pacarebonan, (Pudjiastuti 2000: 488 -500, de Graaf 1987: 48-49, Djajadiningrat 1983: $67-69)$.
} 
adalah Sultan Anom, Kanoman dari Garage? Kedua, Sultan Anom atau Sultan Kanoman yang manakah yang dimaksudkan dalam surat itu? Ketiga, bagaimanakah hubungan Cirebon dengan Belanda pada masa itu, sehingga Sultan Anom bersedia menjadi penyedia bahan-bahan pembuatan rumah yang diinginkan oleh Raad van Indie? Dan keempat, kapankah surat itu ditulis?

Dalam buku katalog naskah Melayu dan Minangkabau koleksi Perpustakaan Universitas Leiden yang disusun oleh Wieringa (1998: 407) surat Sultan Anom itu dicatat sebagai surat ke-17 (No. 80) dari kumpulan surat-surat Banten yang tergabung dalam Cod. Or. $2241 \mathrm{Illb}$. Sebuah naskah yang semula menjadi koleksi Rijks-Instelling ${ }^{2}$. Keterangan yang disampaikan Wieringa mengenai surat itu sangat ringkas, hanya berkenaan dengan ukuran, panjang, dan tebal surat, warna tinta, cap kertas, stempel, dan jenis tulisan. Mengenai deskripsi suratnya Wieringa merujuk pada Klinkert, lampiran no. 8 (188211:103).

Pada buku katalog naskah Melayu, Minangkabau, dan Sumatera Selatan yang disusun oleh Iskandar (1998) surat Sultan Anom tidak disebut secara eksplisit. Iskandar hanya menyatakan "sebuah dompet berukuran $46 \times 30$ $\mathrm{cm}$ berisi surat-surat yang diterima dari Batavia antara tahun 1700-1808. Isinya: (1) 23 surat dari Melayu Peninsula; (2) 31 surat dari pantai barat dan timur Sumatra, dan (3) 20 surat dari Bali dan Banten". Keterangan lebih lanjut mengenai surat-surat ini, Iskandar merujuk pada Klinkert (1882 II: 81 -103) dan Juynboll (1899).

Berdasarkan kedua rujukan di atas, Tijdschrift voor Nederlands Indie (TNI) yang memuat tulisan Klinkert (1882 II: 81-103) diperiksa. Namun, keterangan yang diperoleh mengenai surat Sultan Anom tersebut ternyata sangat singkat, yaitu een brief in Javaansch karakter 'surat dalam tulisan Jawa' (TNI 1882 II: 103. Sementara itu, Juynboll (1899: 314) hanya menyebutkan Cod 2241 yang berisi surat-surat dari Malaka, Sumatra, Bali, Bantam, dan lain-lain itu berasal dari koleksi van der Vlis.

Untuk mendapatkan jawaban atas pertanyaan yang muncul di atas, surat Sultan Anom yang tergabung dalam Cod. Or $2241 \mathrm{IHb} 17$ (No.80) menggunakan pendekatan kodikologis. Pembahasan diawali dengan pembicaraan mengenai sejarah surat, dilanjutkan dengan kajian fisik surat yang meliputi masalah: tataletak, kertas, stempel, tulisan, dan bahasa. Hasil dari pembahasan ini diharapkan dapat menjawab berbagai pertanyaan di atas. Sebagai pelengkap informasi, pada akhir tulisan ditampilkan foto surat, alihaksara, dan terjemahan teks.

$2 \quad$ 'Rijks-instelling' atau lengkapnya Rijks-Instelling tot Opleiding van Indische Ambtenaren adalah lembaga pendidikan untuk pegawai pemerintah Hindia Belanda yang didirikan di Leiden pada tahun 1864. Antara tahun 1871 dan 1878 naskah-naskah koleksi 'RijksInstelling' dialihkan ke berbagai instansi. Sebagian di antaranya pada tahun 1878 dialihkan ke Perpustakaan Universitas Leiden (Wieringa 1998: 283). 


\section{LATAR BELAKANG SUR AT}

Berdasarkan rujukan-rujukan di atas, kita dapat mengetahui asal koleksi surat Sultan Anom sebelum tersimpan di Perpustakaan Universitas Leiden surat itu merupakan koleksi Rijks-Instelling. Dari informasi Juynboll (1899) surat itu berasal dari koleksi van der Vlis. Jika demikian, Rijks-Instelling atau van der Vliskah yang telah salah menempatkan surat itu ke dalam kelompok surat Banten? Salah tempat itu mungkin saja terjadi karena kolektor tidak teliti membacanya. Penulis, ketika pertama-tama melihat surat itu juga mengira bahwa surat tersebut adalah surat Banten, seperti surat-surat yang pernah dibicarakan oleh Ricklefs ${ }^{3}$, yakni surat beraksara Jawa dalam bahasa Melayu yang tersimpan di Algemeen Rijksarchief, Denhaag. Namun, setelah membaca baris pertama teks yang berbunyi Sultan Anom kang alinggi ing Garage, dengan segera saya mengetahui bahwa surat itu bukan surat Banten melainkan surat Cirebon. Agaknya, kolektor pertama surat ini tidak membaca teks sampai akhir baris pertama, tetapi berhenti pada nama Sultan Anom dan langsung mengiranya sebagai Sultan Anom Banten. Oleh karena itu, surat tersebut digabungkan dengan surat-surat Banten. Nama Sultan Anom di Banten memang ada, yaitu nama lain dari Sultan Abunashar Abdul Khahar yang juga terkenal dengan sebutan Sultan Haji ${ }^{4}$.

Surat tersebut dikirim oleh Sultan Anom yang berkedudukan di Garage, Kanoman atau Sultan Kanoman, Cirebon, tetapi nama asli Sultan Anom tidak disebutkan, padahal kebiasaan menyebut gelar tanpa nama seringkali membingungkan ${ }^{5}$. Seperti diketahui, sejak Panembahan Ratu II (Pangeran Girilaya) yang juga dikenal sebagai Raja Cirebon III wafat pada tahun 1662 kekuasaan Cirebon dibagikan kepada kedua putranya; Pangeran Martawijaya yang menjadi Sultan Sepuh I dan adiknya, Pangeran Kertawijaya dinobatkan sebagai Sultan Anom I (Abdurachman 1982: 51) ${ }^{6}$. Sejak itu, wilayah Sultan Sepuh disebut Kasepuhan dan wilayah Sultan Anom disebut Kanoman.

Ketika raja-raja Cirebon mengikatkan diri kepada kompeni dalam suatu perjanjian yang ditandatangani pada tanggal 7 Januari $1681^{7}$, gelar sultan bagi raja-raja Cirebon dicabut dan kembali lagi menjadi Panembahan. Sejak

3 Lihat M.C. Ricklefs "Banten and the Dutch in 1619: Six Early 'pasar malay' Letters" dalam BSOAS, 1976, Vol. XXXIX: 128-136.

Dagh-Register 1912: 124 dan 148.

Sebagai contoh, lihat Leirissa 1997: 205-206 tentang penyebutan nama Sultan Anom.

Mengenai penobatan sultan-sultan Cirebon ada pendapat yang berbeda. Pr. Arif Natadiningrat (1997:233) mengatakan penobatan sultan-sultan Cirebon berlangsung pada tahun 1667, tetapi menurut Abdurachman (1967: 51) penobatan Sultan Cirebon berlangsung pada tahun 1678 untuk tiga sultan Cirebon, yaitu Pangeran Kertawijaya sebagai Sultan Anom, Pangeran Martawijaya menjadi Sultan Sepuh dan Pangeran Wangsakerta sebagai Sultan Cerbon. Menurut Sunardjo (1996: 59), pelantikan Pangeran Martawijaya yang berganti nama menjadi Pangeran Raja Samsuddin dan bergelar Sultan Sepuh I berlangsung pada tahun 1679, sedangkan pelantikan Pangeran Kertawijaya yang berganti nama menjadi Mohammad Badruddin dengan gelar Sultan Anom I berlangsung satu tahun lebih dulu, yaitu 1678.

Lihat Sulistiyono 1997: 85. 
itu, secara politis maupun ekonomi Cirebon berada di bawah kekuasaan dan perlindungan kompeni. Pada tahun 1689 Pangeran Gebang mengikuti rajaraja Cirebon, menempatkan diri di bawah perlindungan kompeni dan pada tahun 1690 penguasa-penguasa Indramayu dan Priangan juga mengambil keputusan yang sama. Setelah tahun 1705, kompeni menjadikan daerahdaerah itu sebagai residen yang dalam istilah administrasi kompeni disebut residensi Cirebon (Abdurachman 1967: 52-53).

Kebiasaan membagi dua kerajaan di Cirebon agaknya berlanjut. Pada akhir abad ke-17, Sultan Anom membagi wilayah kekuasaannya dengan menobatkan putra bungsunya menjadi pangeran merdeka dengan gelar Panembahan. Adapun Kasepuhan, pada tahun 1697 juga membagi dua wilayahnya menjadi Sultan Sepuh dan Sultan Cerbon. Keadaan itu berjalan sampai dengan tahun 1768. Wilayah Kasepuhan utuh kembali, setelah Sultan Cirebon yang banyak melakukan pelanggaran dipecat dan dibuang ke Ambon oleh Belanda ${ }^{8}$.

Kericuhan di Cirebon mencapai puncaknya pada akhir abad ke-18 ketika seorang Sultan Kanoman di tahun 1798 berlaku tidak sesuai dengan tradisi, yaitu menobatkan putra kesayangannya "seorang putra tidak sah" sebagai sultan dengan mengabaikan ahli waris yang sah. Akibatnya muncul protes dan pemberontakan yang bukan saja dilakukan oleh para bangsawan Cirebon melainkan juga para petani kepada Belanda yang dianggap sebagai sumber utama kejahatan yang berlangsung di Cirebon (Abdurachman 1982: $59-60)$.

Berkenaan dengan keterangan-keterangan di atas, kiranya dapat diperkirakan Sultan Anom yang dimaksud dalam surat tersebut adalah Sultan Anom yang bertahta di masa Willem Arnold Alting, Gubernur Jenderal Hindia. Dari penjelasan Paulus (1917) diketahui bahwa Alting adalah Gubernur Jendral Hindia Belanda ke-32 yang menjabat selama 17 tahun $(1780-1797)^{9}$. Berdasarkan hal itu dapat diperkirakan bahwa 'penulis surat' adalah Sultan Anom (Kanoman) yang pada tahun 1798 melanggar aturan tradisi dengan menobatkan putra kesayangannya.

\section{TATA LETAK}

Surat hanya ditulis pada recto, halaman sebaliknya (verso) kosong. Teks surat mulai ditulis pada $10 \mathrm{~cm}$ dari pias atas dan $6 \mathrm{~cm}$ dari pias kiri. Bingkai teks berukuran $25 \times 14 \mathrm{~cm}$.

Surat ini berasal dari seorang raja seperti yang tertera pada baris pertama

\footnotetext{
Lihat arsip VOC, Res. 17/7/1770 (Leirissa 1997: 206).

Willem Arnold Alting lahir di Groningen, Belanda pada tanggal 11 November 1724, ia memulai karirnya di kompeni Belanda pada tahun 1750. Pada tahun 1772 ia menjadi anggota Raad van India dan pada tahun 1780 dipilih sebagai Gubernur Jenderal Hindia Belanda. Ia berperan besar dalam perang Belanda-Inggris yang berlangsung pada tahun 1780-1784. Alting wafat pada tanggal 7 Juni 1800 di Kampung Melayu, Batavia. (lihat J. Paulus dalam Ensyclopaedie van Nederlandsch-Indie 1917: 32).
} 
teksnya: "punika serat tulus sarta iklas saking kawula kangjeng Sultan Anom kang alinggi ing nagari Garage, Kanoman" (ini surat tulus ikhlas dari hamba Kangjeng Sultan Anom yang berkedudukan di negeri Garage, Kanoman). Namun, surat itu tidak memuat semua unsur ilmu surat seperti yang termaktub dalam adat istiadat persuratan Melayu (Kitab Terasul) ${ }^{10}$. Beberapa unsur penting yang terdapat dalam tata aturan surat menyurat seorang raja, seperti kepala surat, hadiah, tarikh, dan sampul surat tidak ada.

Surat yang panjangnya 11 baris terbagi dalam dua alinea. Alinea pertama berisi enam baris dan alinea kedua lima baris. Alinea pertama yang merupakan bagian pertama surat berisi puji-pujian yang menyebutkan nama, gelar, alamat pengirim dan penerima surat, diikuti dengan doa untuk penerima surat. Alinea kedua berisi maksud penulisan surat. Untuk menandai pergantian suasana, teks di bagian kedua ditulis menjorok ke dalam. Penutup surat yang biasanya berisi tarikh dan tempat penulisan surat tidak ada. Surat diakhiri dengan kata titi.

\section{KERTAS}

Bahan surat adalah kertas Eropa yang berukuran 40 x 31,5 cm. Pada kertas terdapat cap kertas ${ }^{11}$ dan cap tandingan ${ }^{12}$. Jika kertas dilipat dua, maka cap kertas terletak di sebelah kanan dan cap tandingan di sebelah kiri. Cap kertas berupa gambar lingkaran bermahkota, di dalamnya terdapat singa bermahkota yang berdiri sambil memegang tongkat bertopi diujungnya dan anak panah, di atas tumpuan bertuliskan VRYHEYT. Di sekeliling lingkaran terdapat moto 'PRO PATRIA EIUSQUE LIBERT ATE,' di bawah lingkaran tertera huruf kapital B. Adapun cap tandingan berupa tulisan D \& C Blauw. Wieringa (1998: 407) mengatakan cap kertas ini sama dengan contoh cap kertas yang terdapat dalam daftar cap kertas Voorn (1960) No. Ill, tetapi dari pengamatan saya contoh cap kertas seperti itu juga terdapat dalam daftar cap kertas Churchill (1935) No. 82. Apabila contoh cap kertas Voorn (1960) No. Ill terdapat pada naskah bertanggal 1749, maka contoh naskah dalam daftar cap kertas Churchill (1935: No. 82) berangka tahun 1740. Menurut Churchill (1935: 13) cap tandingan D \& C BLAUW adalah kependekan dari Dirk \& Co BLAUW, dan kertas yang bercap seperti itu adalah kertas Belanda yang diproduksi pada tahun 1733 - 1827. Churchill, selain memiliki naskah (dengan cap VRYHEYT dan D \& C BLAUW) yang bertanggal 1740, juga mendaftar naskah dengan cap kertas yang sama, dari tahun 1795.

Selain cap kertas dan cap tandingan, pada penampang kertas suratnya

\footnotetext{
${ }_{10}$ Lihat The Legacy of the Malay Letter atau Warisan Warkah Melayu (Annabel Teh Gallop 1994).

Cap kertas adalah bahasa Indonesia untuk watermark. Russel Jones (1981: 172) mengusulkan watermark diterjemahkan sebagai 'tanda kertas,' dan countermark dialihbahasakan 'cap tandingan.'

12 Menurut Heawood (1950: 12) countermark adalah cap kertas yang menemani 'watermark', tampil dalam bentuk huruf (merupakan inisial nama pemilik pabrik atau nama pabrik).
} 
juga terlihat garis tebal dan garis tipis ${ }^{13}$. Garis tebal adalah garis-garis vertikal yang terlihat pada kertas dengan jarak antargarisnya $2,4 \mathrm{~cm}$, sedangkan garis tipis adalah garis-garis horisontal yang jarak antargarisnya cukup rapat, yaitu sembilan garis dalam satu sentimeter.

Jika kita melihat angka tahun contoh-contoh naskah koleksi Voorn dan Churchill yang mempunyai cap kertas sama dengan surat ini, kiranya dapat diperkirakan bahwa surat ini ditulis antara tahun 1780-1797.

\section{STEMPEL}

Pada surat ini terdapat stempel lilin berwarna merah, berbentuk lingkaran dengan diameter $1,5 \mathrm{~cm}$. Di dalam stempel, di tengah lingkaran terdapat lambang VOC berupa gambar tiga huruf kapital, yaitu V, O, dan C. Huruf $\mathrm{O}$ dan $\mathrm{C}$ masing-masing berkait pada kaki huruf V. Di sekeliling lambang VOC terdapat moto dengan tulisan latin yang tidak lagi terbaca jelas: PRE... SRIP... BANDU...

Dalam Kitab Terasul letak stempel pada surat sangat penting, karena berdasarkan letaknya derajat dan pangkat pengirim atau penerima surat dapat diketahui. M. Abdul Nasir (dalam Gallop 1994: 50) menerangkan hubungan letak stempel dengan kedudukan atau jabatan seseorang, yaitu: bila stempel tertera di sudut kanan atas teks, menunjukkan bahwa surat itu adalah surat raja untuk sesama raja atau raja kepada seseorang; jika stempel tertera di pias tengah di atas teks, menunjukkan bahwa surat itu dari menteri kepada menteri atau menteri kepada seseorang; dan jika stempel di ujung sebelah kiri teks, maka surat itu dari hamba kepada hamba atau hamba kepada seseorang.

Sejauh ini, masalah stempel memang belum banyak didiskusikan para pakar pernaskahan. Padahal, menurut Gallop (1994: 44) dari semua unsur persuratan, mungkin stempel adalah yang paling penting, karena dapat menjelaskan berbagai aspek dari: seni, budaya, agama, ekonomi, politik, sampai konsep kronologi dan sejarah. Pada umumnya surat Melayu tidak ditulis oleh pengirim surat, tetapi oleh juru tulis dan biasanya tidak ditandatangani. Oleh karena itu, untuk mengesahkannya, surat dibubuhi stempel. Di sini, fungsi stempel adalah sebagai lambang kekuasaan.

Pada surat ini, stempel diletakkan di sudut kiri atas tetapi bukan di atas teks, melainkan di sisi baris ketiga dan keempat teks. Jika mengacu pada keterangan M. Abdul Nasir, maka dapat diduga bahwa pengirim surat adalah orang yang lebih rendah pangkatnya dari penerima surat. Dalam hal ini, kedudukan Sultan Anom meskipun seorang raja tetapi lebih rendah dari Willem Arnold Alting yang menjabat sebagai Gubernur Jenderal Hindia Belanda. garis tipis.

Mulyadi (1994: 64) menerjemahkan chain-lines dengan garis tebal dan laid-lines dengan 


\section{TULISAN}

Teks surat ini ditulis dengan tulisan Jawa, tinta berwarna hitam. Bentuk huruf kursif dalam ukuran yang tidak terlalu besar atau kecil, tetapi bentuk pepetnya besar, melengkung tinggi ke atas dan miring ke kanan e Layar (untuk bunyi r) berupa garis lurus panjang di atas huruf dan miring ke kanan , dan wulu (untuk bunyi i) berupa dua garis lengkung kecil bertangkup dengan kedua ujung garis kanannya saling bertaut j. Adapun cecak (untuk bunyi 'ng') bentuknya berupa titik di atas huruf $\quad$ tetapi jika dikombinasikan dengan wulu (untuk bunyi 'ing'), maka bentuknya menjadi garis lengkung kecil seperti pada lingsa (, ) yang diletakkan di belakang garis telungkup pada wulu $\left(\boldsymbol{J}^{\prime}\right)$.

Aksara murda atau aksara gedhe dalam teks Jawa biasanya dipakai untuk menulis nama atau tempat, tetapi dalam surat ini tidak digunakan. Pada teks ditemukan tiga buah aksara rekan, yaitu huruf va berupa pa cecak telu ( $(\mathrm{p})$ untuk menulis kata van (baris ketiga), la cecak telu (I ÊEuntuk menulis kata Allah (baris ketiga), dan nga cecak telu (z $\hat{E}^{\prime}$ a untuk menulis kata 'Alla (baris keempat).

Pungtuasi pada teks surat ini ada lima.

1. Pada andhap bentuknya huruf 'nga' bertitik tiga diatasnya 'nga cecak telu' (z $\hat{E}$ - merupakan aksara rekan 'a ${ }^{14}$ - dan tiga garis sejajar di sebelah kanan hurufnya, tetapi garis yang paling dekat dengan huruf melengkung di bawah hurufnya ( $(\quad$ ). Pada andhap adalah tanda pembuka dalam tembang atau surat, variasi lainnya adalah pada luhur ( $\quad \quad$ ) dan pada madya $\left(\begin{array}{l}1 \\ 1\end{array}\right)^{15}$. Dalam penulisan surat resmi, pilihan menggunakan tanda pembuka (pada andhap) sekaligus menunjukkan kedudukan pengirim dan penerima surat. Tanda pembuka dalam surat ini menggunakan pada andhap, ini menunjukkan bahwa pengirim surat, yaitu Sultan Anom sadar akan kedudukannya yang lebih rendah dari Willem Arnold Alting yang menjabat sebagai Gubernur Jenderal Hindia Belanda.

2. Pada adeg-adeg ( ? ) yaitu tanda untuk menunjukkan alinea baru atau awal kutipan.

3. Pada lungsi (, ) adalah tanda koma.

$14 \quad$ Seperti $\varepsilon$ dalam abjad Arab (van der Molen 1993: 66 catatan).

15 Mengenai cara pembentukannya lihat van der Molen (1993: 71). 
4. Pada lingsa (. ) untuk tanda titik.

5. Kata titi $(/ / \mathrm{t}$ i/t $\mathrm{i} / /)$ untuk penutup surat, sebagai tanda tamat atau selesai.

\section{BAHASA}

Bahasa yang digunakan dalam surat adalah bahasa Jawa yang dibubuhi dengan beberapa kosa kata asing, baik bahasa Arab, Belanda, maupun Portugis. Kosa kata Arab antara lain tampak dalam baris pertama "punika serat tulus sarta iklas" 'ini surat tulus dan ikhlas'. Kata iklas dari ikhlas 'tulus hati' atau 'dengan hati yang jujur'. Kata Belanda terlihat pada baris kedua dalam kalimat "kanjeng tuwan mester". Kata mester dari meester yang dalam konteks surat ini berarti 'majikan', sedangkan kata Portugis terlihat pada baris ketujuh dalam kalimat "sampun anyukani kawasa dhateng tuan petor Carbon" 'telah memberi kuasa kepada tuan feitor Cirebon'. Kata petor berasal dari bahasa Portugis feitor. Menurut Pigeaud (1989: 463) artinya ada dua, yaitu (1) pemimpin atau penguasa, dan (2) asisten residen, sedangkan menurut Santa Maria (1967, no. 222) feitor berarti administrator.

Dari pengamatan atas diksi yang digunakan dalam surat, tersirat bahwa kedudukan pengirim memang lebih rendah dari penerima surat, seperti tampak dalam penggunaan nama diri, pengirim surat menyebut dirinya kawula (baris ke-1, 5, 6, 8, dan 9) dan penerima disebutnya kangjeng tuan atau tuan (baris ke-2, 3, 6, dan 7). Selain itu, dalam teks juga tersurat bahwa pengirim surat bersedia melayani penerima surat, terlihat pada baris ketujuh dalam kalimat: "tuan ... asung uninga dhateng kawula yen ... sampun anyukani kawasa dhateng ..." 'tuan ... memberi tahu kepada hamba bahwa ... sudah memberi kuasa kepada ...' dan baris kedelapan pada kalimat: "kawula inggi sadaya amiturut ing sapakajenganipun ..." 'hamba hanya menuruti kehendak tuan ...'

Surat tersebut dibangun oleh dua alinea. Kalimat yang digunakan penulis untuk menandai peralihan suasana dari alinea pertama yang berisi puji-pujian dan doa ke alinea kedua yang merupakan maksud surat, adalah: "sasampuning kadyapunika" 'sesudah itu'. Adapun tanda untuk mengakhiri surat digunakan kata titi yang artinya 'tamat' atau 'selesai' ${ }^{\prime 16}$.

\section{PENUTUP}

Dari pembahasan di atas, pertanyaan yang muncul berkenaan dengan surat ini dapat terjawab. Surat Sultan Anom, Cod.Or 2241 Illb 17 (NO 80) ini ditempatkan dalam kumpulan surat Banten, karena kolektor surat mungkin tidak teliti membaca isinya, sehingga mengira pengirim surat adalah Sultan Anom Banten padahal sebetulnya adalah Sultan Anom dari Kanoman Cirebon. Berdasarkan kajian latar belakang sejarahnya, dapat diketahui penulis surat ini adalah Sultan Anom yang tengah bertahta sebagai Sultan Kanoman ketika

$16 \quad$ Lihat Pigeaud 1989: 570. 
Willem Arnold Alting menjabat sebagai Gubernur Jenderal Hindia Belanda. Dari kajian yang sama pula kita dapat mengetahui hubungan antara Cirebon dengan kompeni Belanda, bahwa sejak tahun 1681 Cirebon sudah berada di bawah kekuasaan kompeni Belanda. Oleh karena itu, tidak heran apabila Sultan Anom dalam suratnya menyatakan kesediannya menjadi 'pelayan' Willem Arnold Alting dan Raad van Indie dalam rencana pembuatan rumah baru mereka di Indramayu. Berdasarkan hal itu dan kajian kertasnya, waktu penulisan surat Cod.Or 2241 Illb 17 (NO 80) juga dapat diperkirakan, yaitu antara tahun 1780 - 1797, atau setidaknya di tahun terakhir Willem Arnold Alting berkuasa, yakni tahun 1797.

\section{DAFTAR ACUAN}

Abdurachman, Paramitha R. 1982. Cerbon. Jakarta: Sinar Harapan.

Churchill, W. 1935. Watermarks in Paper. Amsterdam: Menno Hertzberger.

Djajadiningrat, Hoesein. 1983. Tinjauan Kritis tentang Sajarah Banten. Jakarta: Jambatan.

Gallop, Annabel Teh. 1994. The Legacy of The Malay Letter atau Warisan Warkah Melayu. London: The British Library.

Heawood, Edward. 1950. Watermarks Mainly of The 17 and la centuries. Hilversum: The paper Publications Society.

Iskandar, Teuku. 1998. Catalogue of Malay, Minangkabau, and South Sumatran Manuscripts in The Netherlands. Leiden: Documentatie bureau Islam-Christendom.

Jones, Russel. 1981. "Penjelasan Lanjut Mengenai Manuscrip Melayu" dalam Jamilah Haji Ahmad (ed.) Kumpulan Esei Sastera Melayu Lama. Kuala Lumpur: Dewan Bahasa dan Pustaka: $160-174$.

Juynboll, H.H.1899. Catalogue van de Maleische en Sundaneesche Handschriften der Leidsche University Bibliotheek. Leiden: Brill.

Klinkert, H.C. 1882. "Verzameling van Maleische Brieven, voorhanden in de Rijksbibliotheek te Leiden". Tijdschrifi voor Nederlands Indie (TNI) II.

Lapian, AB dan Edi Sedyawati. 1997. “Kajian Cirebon dalam Kajian Jalur Sutra” dalam Cirebon sebagai Bandar Jalur Sutra. Kumpulan makalah diskusi ilmiah. Jakarta: Departemen Pendidikan dan Kebudayaan RI.

Leirissa, R.Z. 1997. "Cirebon dalam Arsip VOC" dalam Cirebon sebagai Bandar Jalur Sutra. Kumpulan makalah diskusi ilmiah. Jakarta: Departemen Pendidikan dan Kebudayaan RI.

Mulyadi, Sri Wulan Rujiati. 1994. "Kodikologi Melayu di Indonesia", dalam Lembaran Sastra edisi khusus No. 21. Depok: Fakultas Sastra Universitas Indonesia.

Molen, W. van der. 1993. "Javaans Schrift". Semaian 8. Leiden: Vakgroep Talen en Culturen van Zuidoost-Azie en Oceanie.

Natadiningrat, Arif. P.R. 1997. "Potensi dan Prospek Perekonomian Cirebon" dalam Cirebon sebagai Bandar Jalur Sutra. Kumpulan makalah diskusi ilmiah. Jakarta: Departemen Pendidikan dan Kebudayaan RI

Paulus, J. 1917. Ensyclopaedie van Nederlandsch-Indie, le deel. Gravenhage/Leiden: Nijhoff en Brill.

Pigeaud, Th.G.Th. 1989. Javaans - Nederlands Woordenboek. Dordrecht/Providence: Foris

Pudjiastuti, Titik. 2000. Sajarah Banten. Suntingan Teks dan Terjemahan disertai Tinjauan Aksara dan Amanat. Depok: Pascasarjana Fakultas Sastra Universitas Indonesia. Disertasi (belum diterbitkan).

Santa Maria, Luigi. 1967. Iprestiti Portoghesi nel Malese-Indonesiano. Napoli: Institute Orientale.

Sulistyono, Singgih Tri. “Dari Lemahwungkuk hingga Cheribon: Pasang Surut Perkembangan Kota Cirebon sampai Awal Abad XX" dalam Cirebon sebagai Bandar Jalur Sutra. Kumpulan makalah diskusi ilmiah. Jakarta: Departemen Pendidikan dan Kebudayaan RI. 
Voorn, H. 1960. De Papiermolens in de Proviencie Noord-Holland. Haarlem: Papierwereld. Wieringa, E.P. 1998. Catalogue of Malay and Minangkabau Manuscripts in The Library of Leiden University and Other Collection in The Netherlands. Vol. 1, Leiden: Legatum Warnerianum.

\section{LAMPIRAN}

Alihaksara

1. Punika serat tulus sarta iklas saking kawula kangjeng Sultan Anom kang alinggi ing nagari Garage Ka |

2. noman kitun tabe katha-katha, katur dhateng kangjeng tuwan mester Welem Amol Alting gurnadur jenderal |

3. mi wa dhateng tuan Rad vanlndiya sadaya ingkang alinggi ing nagari Batawiya kang sinungaken dening Allahu tang |

4. 'Ala kang atas kawasa, andarbeni paparentahan ing nagari atas angin miwa ing nagari bawangin sadaya kala |

5. wan ingkang mogi sinungan umur panjang dening Alia sarta salamet kalawan kasarasan dados pangayuban kawula ing sala |

6. mi laminipun, ing dalem dunya puniki.

7. Sasampuning kadya punika awiyosi jengandika sarta tuan Rad pan Indiya sa |

8. daya asung uninga dhateng kawula yen ajeng andika sadaya sampun anyukani kawasa dhateng tuan, petor Carbo |

9. n andamel pondhok ing nagari Dramajeng ingkang anyar kawula inggi, sadya hamiturut ing sapakajenganipun atulung ing |

10. kempeling dangdananing pondhok ing saparantos sarya ing sakawawinipun saesthi prada kawula kawrat sadaleming serat. |

11. titi

\section{Terjemahan}

1. ini surat tulus ihlas dari hamba kanjeng Sultan Anom yang berkedudukan di negeri Garage, Ka

2. noman kirim banyak salam kepada kanjeng tuan Mister Wilem Arnold Alting Gubernur Jendral

3. dan juga semua tuan Raad van India yang berkedudukan di Betawi yang dikaruniai Allah huta

4. 'Ala yang kuasa yang menguasai pemerintahan di semua negeri atas angin dan bawah angin

5. dan yang semoga diberi umur panjang oleh Allah serta sehat selamat (itulah) yang saya harapkan selama-lamanya di dalam dunia ini.

6. Sesudah itu, seperti (yang) dikehendaki semua tuan Raad van India

7. yang memberitahukan kepada hamba bahwa tuan-tuan

8. semua sudah memberi kuasa kepada petor Carbo

9. untuk membuat rumah baru di Dermayu, hamba bersedia menuruti apa yang menjadi keinginan (tuan) menolong

10. mengumpulkan bahan-bahan dan peralatan untuk pembuatan rumah semampu hamba sungguh (seperti) pujian hamba yang termuat dalam surat ini

11. selesai. 


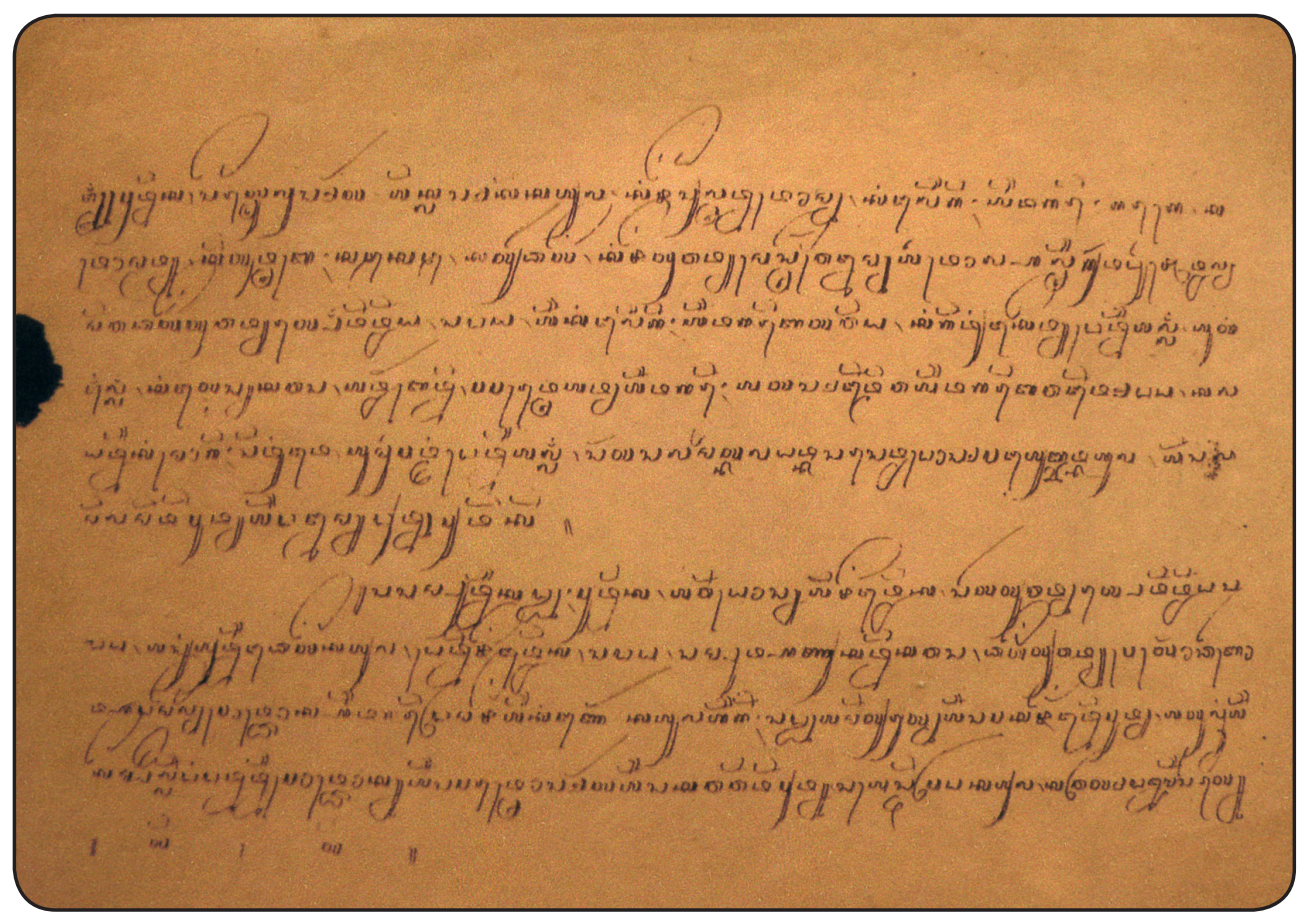

\section{COD. OR. 2241 ILLB 17 (No. 80)}

